\title{
Ultrastructural Study of the Neural Fat-body System in the Cockroach Periplaneta americana*
}

\author{
P. J.Gardner and D.J.Weidler \\ Department of Anatomy, University of Nebraska, College of Medicine, Omaha, Nebraska \\ and Upjohn Center for Clinical Pharmacology, University of Michigan Medical Center, \\ Ann Arbor, Michigan, USA
}

Received February 27, 1975

\begin{abstract}
Summary. The neural fat-body system of the ventral nerve cord in the cockroach Periplaneta americana was studied with the light and electron microscopes. This adipose tissue surrounds the connectives and extends over the ganglia. The adipose cells typically contain numerous extremely large lipid inclusions, pleomorphic lysosomes, and tightly packed glycogen granules. The neural lamella consists of a thick inner layer rich in collagen fibers and a thin outer layer of granular material. At points where the fat body is attenuated, this granular layer is split and the outer lamina is reflected superficially to ensheath and apparently to anchor the fat body.
\end{abstract}

Key words: Neural fat body - Periplaneta americana — Perineurium — Neural lamella — Granular layer.

\section{Introduction}

Although the neural lamella and perineurium which surround the insect nervous system have been extensively studied (Scharrer, 1939; Ashhurst, 1959, 1961 ; Ashhurst and Chapman, 1961; Smith and Treherne, 1963; Maddrell and Treherne, 1967; Smith, 1967), the existence of the neural fat-body sheath was reported relatively recently in the stick insect Carausius morosus (Maddrell and Treherne, 1966; Treherne and Maddrell, 1967).

As pointed out by Huddart et al. (1973), there are two possible major functions of the fat-body sheath, protection and nutrition. In addition, the observation that a sheath of this type is commonly, although not exclusively, found in insects with unusual cationic concentrations in the hemolymph suggests that this structure functions in the ionic regulation of the central nervous system. Based on physiological studies in C. morosus, this hypothesis already has been advanced (Maddrell and Treherne, 1966; Weidler and Diecke, 1969, 1970a, 1970 b; Huddart, 1972). Since C.morosus is a herbivorous insect with such unusual cationic concentrations in its hemolymph, the question arises as to what function such a fat-body sheath may have in insects with conventional ionic concentrations in their hemolymph. Before considering this question, it is necessary to establish the presence and to provide a thorough anatomical description of the fat-body sheath in at least one representative of this group.

Send offprint requests to: Paul J. Gardner, Ph. D., Department of Anatomy, University of Nebraska, College of Medicine, 42nd and Dewey Avenue, Omaha, Nebraska 68105, U.S.A.

* Supported by USPHS Grant FR 5391. 
The cockroach Periplaneta americana was selected because the existence of a fat-body sheath in this species has been discounted by several investigators (Twarog and Roeder, 1956; Treherne, 1961; Maddrell and Treherne, 1966). In a more recent study, it was demonstrated that in adult male $P$. americana the neural fat body occupies approximately $22 \%$ of the total nerve cord volume (Weidler et al., 1971). The present work deals with the ultrastructure of the fat body adhering to the ventral nerve cord of $P$. americana. Several features of the neural lamella and perineurium also are described. The fat-body system of the brain and peripheral nerves is not considered, and no comparison is made with fat-body tissue in general.

\section{Materials and Methods}

For fixation each insect was injected with Karnovsky's solution. The ventral nerve cord plus surrounding sheath were exposed, flooded in situ with fixative, carefully extirpated, and placed in a container of the same solution. After fixation at room temperature for $1 \frac{1}{2}$ to 2 hours, the tissue was washed overnight in cold buffer, post-fixed in $1 \%$ osmium tetroxide, dehydrated in ethanol, and embedded in Araldite. Several paraffin embedded specimens were sectioned serially for light microscopic study.

Thick sections of plastic embedded tissue, stained with toluidine blue, served for orientation. Thin sections were stained with uranyl acetate and lead citrate and viewed with an RCA EMU 3G electron microscope.

\section{Results}

Serial sections of the ganglion chain of Periplaneta firmly establish that fat body is present around connectives (Figs. 1, 5) and appears to extend over ganglia. However, the amount of this fat tissue varies according to age, sex, and nutritional state of the specimen. In the female the sheath is considerably thicker than in the male, and in both sexes it becomes depleted due to inadequate diet or old age.

Unlike that of Carausius, the fat-body sheath of Periplaneta is closely applied to the neural lamella and its pattern of distribution is much more irregular. It seems to fill recesses between and around connectives, but is attenuated in ganglionic areas. Because of these irregularities and its fragility, demonstration of continuity of the sheath over the length of the chain is difficult.

The ultrastructure of the perineurium and neural lamella has been studied by previous investigators, e.g., Maddrell and Treherne (1967), Lane and Treherne (1972), Smith and Treherne (1963). Our micrographs show the more superficial cells of the perineurium to be packed with microtubules. At points of tight junction the lumina of these microtubules appear to be continuous with channels of the neural lamella (Fig. 2). Higher magnifications of the neural lamella show it to consist of a relatively thick inner layer and a much thinner outer layer (Fig. 3). The inner layer is formed by complex lamellae rich in multidirectional collagen fibers aligned parallel to the surface of the cord and embedded in a granular material or ground substance. The outer layer consists entirely of the same granular substance. Intralamellar spaces are often located beneath the granular layer (Figs. 3, 5). In areas where there is attenuation of the fat body, this same granular layer splits to completely ensheath the cellular elements of the fat body (Fig. 3). In regions where the fat body is more massive, branches of the layer form septa between groups of fat cells. 


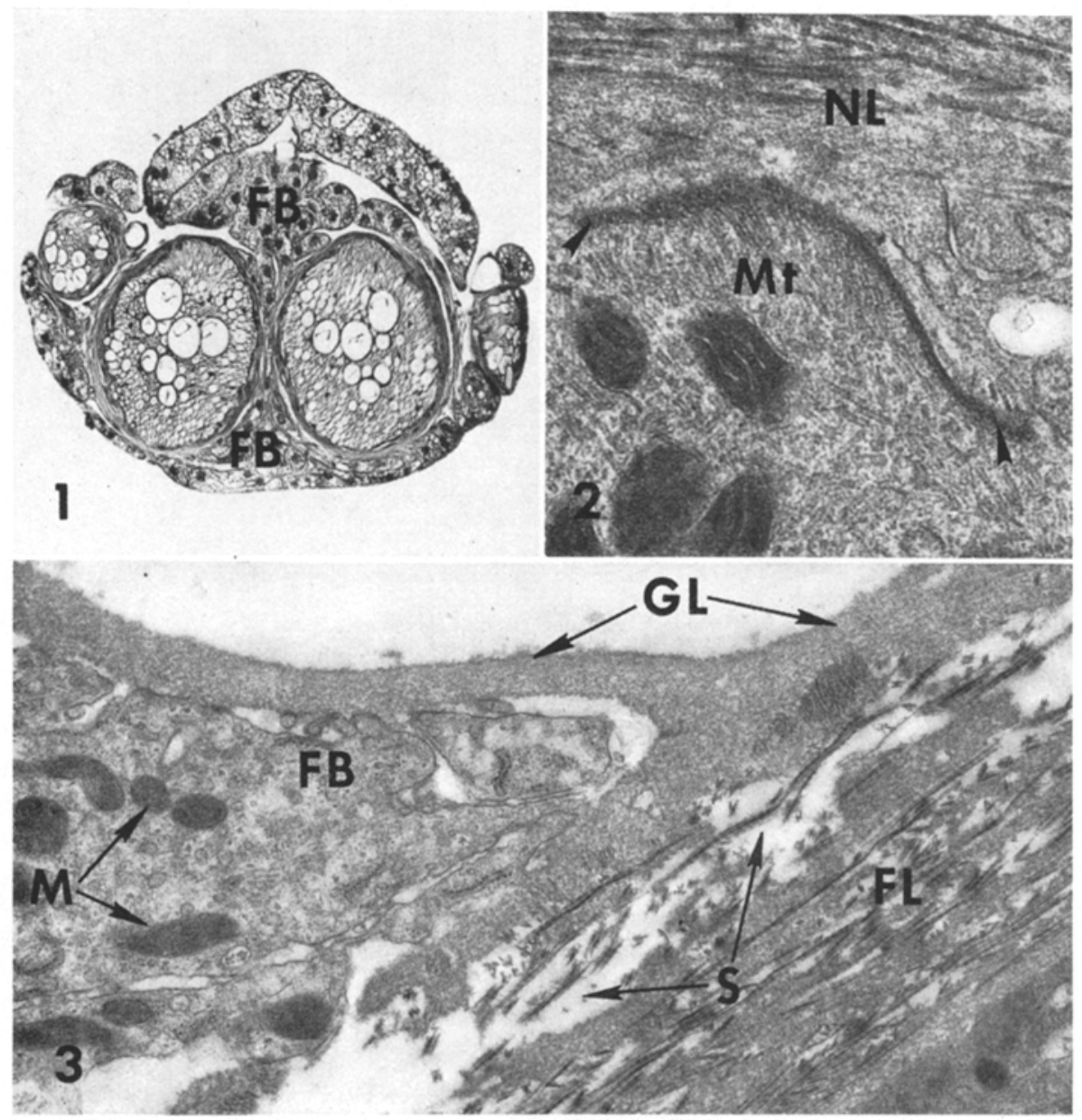

Fig. 1. Paired abdominal connectives $(C)$ surrounded by fat body $(F B) . \times 75$

Fig. 2. Longitudinal profiles of microtubules $(M t)$ in perineurial cell suggesting continuity between their lumina and intralamellar spaces of neural lamella $(N L)$ in areas of tight junction (arrows). $\times \mathbf{4 4 0 0 0}$

Fig. 3. Granular layer $(G L)$ of neural lamella, split to ensheath fat-body cell $(F B)$. Mitochondria $(M)$. In adjacent fibrous layer $(F L)$, note same granular material interspersed between layers of multidirectional collagen fibers. Intralamellar spaces $(S) . \times \mathbf{2 2 0 0 0}$

In the adult cockroach, the fat-body sheath consists almost entirely of one type of cell. Its irregular shape is explained by its adjustment to the available spaces. The ovoid nuclei are moderately electron dense with scattered clumps of chromatin and an extremely dense, fragmented nucleolus (Fig. 4). The lipid inclusions are highly variable in size; the distribution of glycogen varies among animals and regions of the same animal (Figs. 4,5 ).

Mitochondria are circular to elongate in profile (Fig. 3). Extremely dense granular matrices are interrupted by narrow cristae. Clumps of granular endo- 

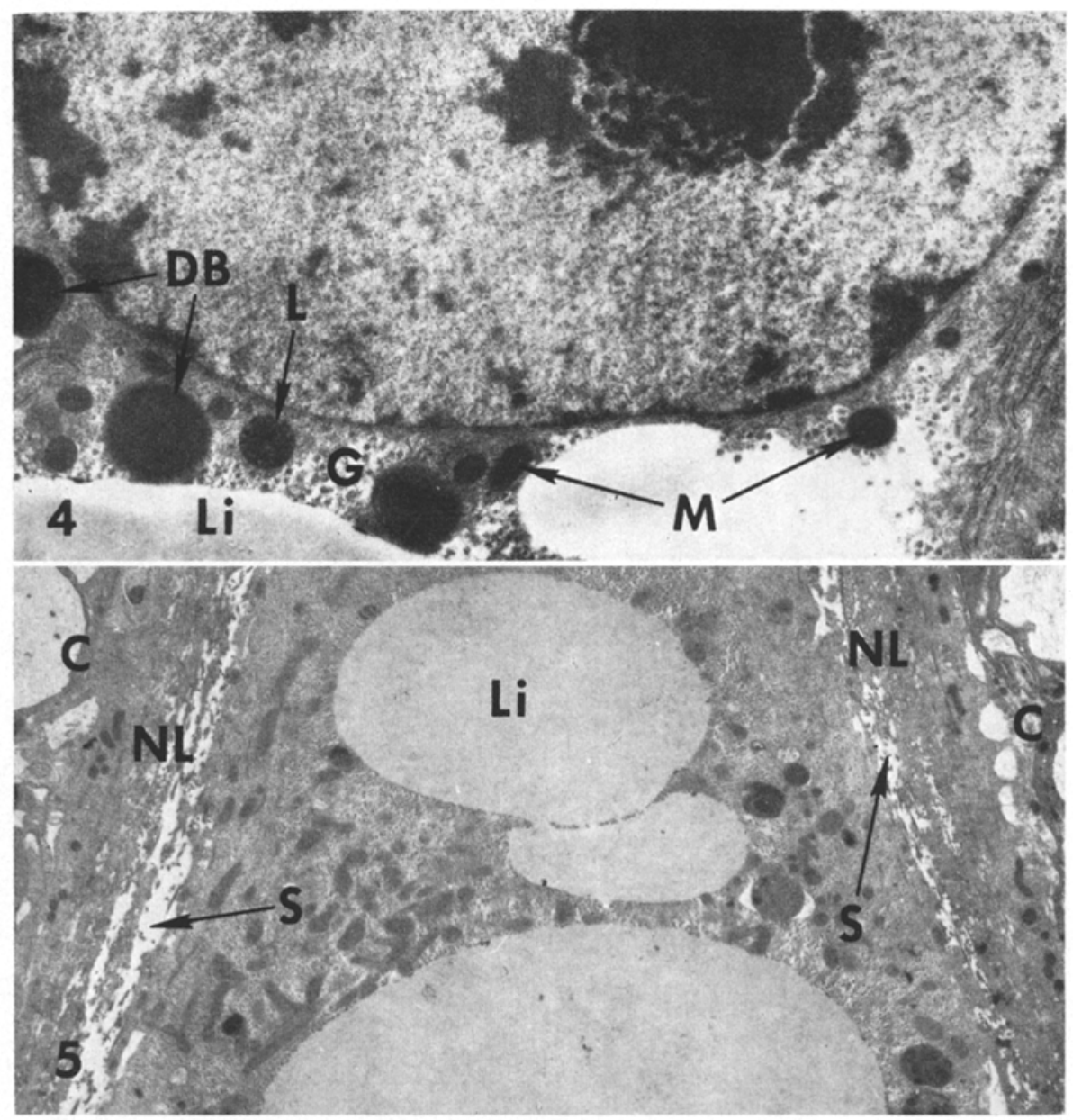

Fig. 4. Juxtanuclear region of fat-body cell with abundant glycogen granules $(G)$ and large lipid bodies $(L i)$. Extremely electron dense structures include small mitochondria $(M)$, a Iysosome $(L)$, and larger "dense bodies" $(D B)$, perhaps lipid in character. $\times 4200$

Fig. 5. Fat-body cells between abdominal connectives $(C)$ with large lipid inclusions $(L i)$. Note numerous spaces $(S)$ in adjacent layers of neural lamellae $(N L) . \times 11300$

plasmic reticulum are scattered throughout most cells and occasionally form circlets or parallel pairs of cisternae (Fig. 4). Spherical bodies (Fig. 4) resemble lysosomes or lipofuscin pigment granules. Both types are more numerous in those cells in which lipid inclusions appear to be replaced by vacuoles containing glycogen rosettes. Multivesicular bodies and membrane-bounded spherical aggregations of granules are also frequently observed in these cells.

\section{Discussion}

The purpose of the present study was to describe the extent and the ultrastructure of the neural fat-body system in an insect species which has conventional ionic concentrations in its hemolymph and to determine if its location and com- 
position are such that it could participate in the regulation of ions in the nervous system.

The present study verifies the finding of Weidler et al. (1971), that in adult male $P$.americana the cytologically complex neural fat body occupies at least one-fifth of the total nerve cord volume. In female $P$. americana, the neural fat body occupies approximately twice as much of the total nerve cord volume as in males. These quantitative relationships are also affected by the age and diet of the animal.

Since the granular layer of the neural lamella is reflected to enclose adjacent elements of the fat body, it forms an apparently uninterrupted barrier around both nerve cord and adherent adipose cells and thus could play an effective role in regulating the movement of ions between the hemolymph and the nervous system. Because of this relationship, we refer to the neural lamella and enclosed fat body as the neural fat-body system.

Evidence that the fat body is the site of conversion of certain substances to energy sources has been reviewed by Kilby (1963). It seems obvious that these energy sources are then utilized in the metabolism of glial cells and neurons. However, the same sources could provide energy for an active transport mechanism located in the neural fat-body system. The difference between the ionic composition of extra-axonal fluid and that of the medium bathing the ventral nerve cord of Periplaneta (Treherne and Moreton, 1970; Treherne and Pichon, 1972; Treherne et al., 1973; Wendt and Weidler, 1973) probably could not be produced without the aid of an active transport system.

In developing the concept of regulation of ions in the nervous system of insects, two components are necessary. First, there must be an active transport system, which requires an energy source, and secondly, there must be a diffusion barrier, which may or may not be located in a site other than that of the active transport system (Weidler and Diecke, 1969). The diffusion barrier probably resides in the perineurium (Lane and Treherne, 1972; Treherne et al., 1973). The active transport mechanism could be located in the neural fat-body system, the perineurium, or the glial elements surrounding the axons of the nerve cord.

If the site of active transport in the nervous system of $P$.americana is located in the granular layer of the neural fat body, as suggested for other species by Weidler and Diecke (1970a), and Weidler et al. (1974), then it also may be postulated that in Periplaneta the entire fat-body system (i.e., fat body and neural lamella) may be involved since the granular layer covering the fat-body cells is continuous with that of the neural lamella. The granular layer of the neural lamella is present, and may provide active transport, in areas where there are no fat-body cells. This observation counters the contention that, because the fat body is absent over peripheral nerves, it cannot be the site of ionic regulation. Theoretically, complete cells are not needed to sustain active transport, since such transport obviously occurs across the membranes of individual cells. Therefore, an acellular mechanism of active transport, as suggested here for the granular layer, is not unreasonable.

The observation in the present study of intralamellar spaces beneath the granular layer (Figs. 3, 5) tends to support the hypothesis that this layer is the site of active transport of molecules. If sodium ions are actively transported 
across the granular layer, then water may follow by passive diffusion and produce the intralamellar spaces. Sodium ions would then diffuse across the perineurium into the extracellular fluid surrounding neurons and glial cells.

In summary, the present work demonstrates that in Periplaneta, the outer granular layer that envelops the neural fat body is continuous with the granular layer of the neural lamella in areas where fat-body cells are absent and that together they form an uninterrupted barrier around the ventral nerve cord. Earlier observations (Weidler et al., 1971), that the neural fat body of Periplaneta occupies one-fifth or more of the total nerve cord volume, are confirmed. The location and ultrastructural composition of the neural fat-body system in P.americana are consistent with the theory that it could be the site of an active transport component of a more complex system that controls the movement of ions.

\section{References}

Ashhurst, D. E.: The connective tissue sheath of the locust nervous system: a histochemical study. Quart. J. micr. Sci. 100, 401-412 (1959)

Ashhurst, D. E.: A histochemical study of the connective tissue sheath of the nervous system of Periplaneta americana. Quart. J. micr. Sci. 102, 455-461 (1961)

Ashhurst, D. E., Chapman, J.A.: The connective tissue sheath of the nervous system of Locusta migratoria: an electron microscope study. Quart. J. micr. Sci. 102, 463-467 (1961)

Huddart, H.: Fine structure of the neural fat-body sheath in the stick insect and its physiological significance. J. exp. Zool. 179, 145-156 (1972)

Huddart, H., Greenwood, M., Oates, K.: Fine structure of the abdominal neural fat-body sheath in the stick insect (Carausius morosus, Br.). J. Morph. 140, 87-104 (1973)

Kilby, B. A.: The biochemistry of the insect fat body. In: Advances in insect physiology, vol. I (ed. by Beament, J. W. L., Treherne, J. E., and Wigglesworth, V. B.), p. 111-174. London and New York: Academic Press 1963

Lane, N. J., Treherne, J. E.: Studies of perineurial junctional complexes and the sites of uptake of microperoxidase and lanthanum in the cockroach central nervous system. Tissue and Cell 4, 427-436 (1972)

Maddrell, S. H. P., Treherne, J. E.: A neural fat-body sheath in a phytophagous insect (Carausius morosus). Nature (Lond.) 211, 215-216 (1966)

Maddrell, S. H. P., Treherne, J. E.: The ultrastructure of the perineurium in two insect species, Carausius morosus and Periplaneta americana. J. Cell Sci. 2, 119-128 (1967)

Scharrer, B. C. J.: The differentiation between neuroglia and connective tissue sheath in the cockroach (Periplaneta americana). J. comp. Neurol. 70, 77-88 (1939)

Smith, D. S.: The trophic role of glial cells tn insect ganglia. In: Insects and physiology (ed. by Beament, J. W. L., and Treherne, J. E.), p. 189-198. Edinburgh and London: Oliver and Boyd, (1967)

Smith, D. S., Treherne, J. E.: Functional aspects of the organization of the insect nervous system. In: Advances in insect physiology, vol. 1 (ed. by Beament, J. W. L., Treherne, J. E., and Wigglesworth, V. B.), p. 401-484. London and New York: Academic Press 1963

Treherne, J. E.: Sodium and potassium fluxes in the abdominal nerve cord of the cockroach, Periplaneta americana. J. exp. Biol. 38, 315-322 (1961)

Treherne, J. E., Maddrell, S. H. P.: Membrane potentials and the nervous system of a phytophagous insect (Carausius morosus). J. exp. Biol. 46, 413-421 (1967)

Treherne, J. E., Moreton, R. B.: The environment and function of invertebrate nerve cells. Int. Rev. Cytol. 28, 45-88 (1970)

Treherne, J. E., Pichon, Y.: The insect blood-brain barrier. Adv. Insect Physiol. 9, 257-313 (1972)

Treherne, J. E., Schofield, P. K., Lane, N. D.: Experimental disruption of the blood-brain barrier system in an insect (Periplaneta americana). J. Exp. Biol. 59, 711-723 (1973) 
Twarog, B. M., Roeder, K. D.: Properties of the connective tissue sheath of the cockroach abdominal nerve cord. Biol. Bull., Woods Hole 111, 278-286 (1956)

Weidler, D. J., Diecke, F. P. J.: The role of cations in conduction in the central nervous system of the herbivorous insect Carausius morosus. Z. vergl. Physiol. 64, 372-399 (1969)

Weidler, D. J., Diecke, F. P. J.: The regulation of sodium ions in the central nervous system of the herbivorous insect Carausius morosus. Z. vergl. Physiol. 67, 160-178 (1970a)

Weidler, D. J., Diecke, F. P. J.: Hemolymph ionic concentrations and sodium ion regulation by the neural sheath in two stick insect species Diapheromera femorata and Carausius morosus. Z. vergl. Physiol. 69, 311-325 (1970 b)

Weidler, D. J., Earle, A. M., Myers, G. G., Gardner, P. J.: Effect of metabolic inhibition on sodium ion exchange in the ventral nerve cord of Melanoplus differentialis. Comp. Biochem. Physiol. 49A, 207-214 (1974)

Weidler, D. J., Myers, G. G., Gardner, P. J., Bennett, A. L., Earle, A. M.: Defects in the experimental design of radioisotopic studies on the insect nerve cord. $Z$. vergl. Physiol. 75, 352-366 (1971)

Wendt, R. B., Weidler, D. J.: Effect of external chloride replacement on action potentials of giant axons in Periplaneta americana. Comp. Biochem. Physiol. 44 A, 1303-1311 (1973) 